\title{
Evolutionary mechanisms of choice: Hayekian perspectives on neurophilosophical foundations of neuroeconomics
}

\author{
Carsten Herrmann-Pillath (1D) \\ Max Weber Centre for Advanced Cultural and Social Studies, Erfurt University, Steinplatz 2, 99085 Erfurt, \\ Germany \\ Email: carsten.herrmann-pillath@uni-erfurt.de
}

(Received 6 July 2019; revised 5 September 2020; accepted 18 September 2020; first published online 15 December 2020)

\begin{abstract}
Hayek's seminal contribution to theoretical neurosciences, The Sensory Order (1952) remains neglected in current efforts at integrating the neurosciences, psychology and economics. I defend the view that Hayek presents the case for an evolutionary alternative to leading paradigms in the field and look at two in more detail: the good-based model in neuroeconomics and the dual systems approach in behavioural economics. In both cases, essential Hayekian insights remain valid in the context of modern neuroscience, allow for taking account of recent research, and sketch a dynamic and selectionist model of choice.
\end{abstract}

Keywords: Hayek's Sensory Order; good-based model; dual systems; grounded cognition; multi-level evolution

JEL codes: B41; D91

\section{Hayek and the foundations of neuroeconomics}

Economics has been undergoing a profound disciplinary transformation in the recent decades (for a survey that matches with the views endorsed in this paper, see Ross 2014). One of the most remarkable trends is the revival of psychological reasoning and research, which may be conceived as reflecting the broader phenomenon of a naturalistic turn, i.e. the increasing use of theories and methods of the sciences in economics. A significant part of this research is running under the label of 'behavioural economics', to which the field of neuroeconomics has been added, although the relationship between the two is not yet settled: behavioural economics is mostly based on psychological theories and hypotheses, without necessarily aiming at further grounding in neuroscience; at the same time, neuroscience evidence for certain fundamental conceptual frames, such as the 'dual systems' view, is shaky (a point made early by Kable and Glimcher 2007). 
This paper explores philosophical foundations of neuroeconomics in introducing Hayek as a precursor who is so far neglected in positioning the new subdiscipline (for rare exceptions see Basso et al. 2010 and Takahashi and Egashira 2013; there is a related effort in positioning Hayek as precursor to behavioural economics, see the edited volume by Frantz and Leeson 2013). I refer to his remarkable book The Sensory Order (Hayek 1952) which has many ramifications in his very broad-ranging oeuvre (Vanberg 2018), but which has been ignored by economists for decades, and even today is only fully recognized in the Austrian economics school of thought (see the edited volumes Butos 2010 and Marsh 2011), while in relevant specialist fields such as neuroeconomics Hayek is absent (and vice versa; Austrian economists refer to neuroeconomics only selectively to endorse Hayek's view, e.g. Butos and McQuade 2015). This is surprising because Hayek's book is today recognized by neuroscientists as prescient of many important developments in the discipline, and together with Donald Hebb's (1949) work can be counted as seminally establishing connectionism as an analytical paradigm in the brain sciences (Steele 2002; Fuster 2011; McDowell 2019). Connectionism is the major alternative to modular and syntax-based computational models of the brain (for an overview, see Buckner and Garson 2019) and underlies modern theories of neural networks, which emphasize endogenous and decentralized learning via evolving neural connections.

In our context, Hayek is also inspiring because he is one of the first scholars who explicitly adopted a 'neurophilosophical' approach. This is the perspective of the current paper. Today, neurophilosophy comes in various versions, most of them motivated by standard topics in the philosophy of mind. Neurophilosophy partly differs from the philosophy of the neurosciences in the narrow sense, which is conceived as a specialization in the philosophy of science (e.g. Craver 2007), whereas neurophilosophy is heavily geared towards foundational issues in ontology and metaphysics (a most influential contribution in terms of the latter is the work of the Churchlands (Churchland 1989); for a survey, see Bickle et al. 2019). The version of neurophilosophy that I pursue is based on Hayek's approach and is best characterized as 'brain-based philosophy' or 'thinking from the brain'. That formula is championed by Northoff (2014: 212ff), who, however, does not seem to be aware of Hayek.

Philosophical reflection is needed when principled questions of cross-disciplinary relations are raised, such as when many economists question whether neuroscience is relevant at all for economics (for a seminal assessment of the controversies with various important contributions, see the special issue in Economics \& Philosophy, 2008). They define as objects of economics the systems which comprise markets and individuals, see these as the most important components (adding other entities such as firms or government etc.), and focus on population-level regularities of processes materializing in these systems (Ross 2014). That means, individual-level behavioural phenomena would simply fall outside of the scope of economics as a science and are explanatorily irrelevant (Gul and Pesendorfer 2008).

Neuroeconomics directly challenges these ideas since some leading protagonists claim that neuroscience can provide an empirical basis for the standard economic model of choice (dubbed the 'neuroclassical' view by Camerer 2013 who represents another view established early in Camerer et al. 2005). This is significant, because many critics of certain standard assumptions of economics claim that they are 
empirically futile and even falsified, and because it opens another battle line in the debate about behavioural economics, as mentioned. In this paper I defend the view that Hayek's approach offers a solution to both principled controversies. This is to suggest an evolutionary framework.

Hayek's thinking is generally characterized as 'evolutionary'; however, this requires clarification in the course of my reasoning. The potential relevance of Hayek's evolutionary views is salient in recent neuroeconomics debates in which the standard model, directly informed by economics, is challenged by views that approach choice as a dynamic process of variation and selection, hence as 'evolutionary', in the more specific meaning of 'evolutionary mechanisms' (Hunt and Hayden 2017 versus Padoa-Schioppa and Conen 2017). In these debates, Hayek remains mostly neglected (but see McDowell 2019). We can now ask whether Hayek's Sensory Order may be regarded as a founding document of this alternative view on neuroeconomics, and accordingly as a new view on the integration of economics and psychology as informed by neuroscience. This is also productive in the context of internal debates over the status of neuroeconomics in the neurosciences which has even motivated a terminological shift away from 'neuroeconomics' to 'decision neuroscience', thus creating a tension between economics and neuroscience regarding the sub-disciplinary identification of the field (Bossaerts and Murawski 2015).

One problem with interpreting 'evolutionary' in the Hayekian context is that the Sensory Order only indirectly discusses a topic that is very prominent in Hayek's later evolutionary thinking about culture and group selection. This is salient in the context of the other important strand of the naturalistic turn, i.e. experimental economics as established by Vernon Smith, a professed Hayekian, and referred to as 'ecological' (Smith 2004). This point has been highlighted in the recent Austrian economics literature and, I think, has been satisfyingly resolved (for instance, Boettke et al. 2013). I come back to this important question in the conclusion. At this point, I emphasize that the focus on choice justifies postponing the issue, and the implicit individualism of the Sensory Order (Di Iorio 2010) matches with the neuroeconomics concentration on individual acts of choosing, i.e. decisions.

The paper proceeds as follows. In section 2 I briefly sketch the main ideas of the Sensory Order and locate them in the context of modern neuroscience, with emphasis on principled aspects, and less on detail, which necessarily diverge as Hayek's book represents the state of neuroscience six decades ago. This defines the approach of section 3: I discuss two basic alternatives in relating neuroscience with economic theories of choice, the 'good-based model' directly matching with neoclassical models, the 'dual systems model' in behavioural economics, and the evolutionary approaches that have recently emerged in both fields. The latter, I suggest, can be grounded neurophilosophically on Hayek. In my conclusion I pick up the question how the Sensory Order relates to Hayek's view on cultural evolution, which builds the bridge to the ecological approaches to human behaviour as championed by Vernon Smith. This converges with recent developments in the emerging fields of social and cultural neuroscience, thus closing the circle in relation to Hayek's oeuvre. 


\section{Hayek's neurophilosophy and its relevance today}

\subsection{The 'Sensory Order', in a nutshell}

Hayek begins by recognizing that there is a fundamental ontological gap between the brain and the world, or, what he calls 'sensory order' versus the 'physical order' (Hayek 1952: 4ff., 14). No third-person objective description of the world survives the transition across the body/world boundary, because all information is coded exclusively in neuronal signals of basically the same quality. As a consequence, even if one approaches neuronal phenomena from the third-person perspective, how the world is represented by the brain remains subjective in the sense that we cannot ultimately determine the contents ('qualities') of this internal representation simply by inference from properties of their external objects. As commentators have duly emphasized, this straddles apparently contradictory positions: a science-based approach to cognition on the one hand, but radical subjectivism on the other (Butos and McQuade 2015). This is how the Sensory Order connects with Hayek's general theory of knowledge.

Hayek simplifies the neuroscience knowledge of his day to highlight his essential conclusions, and he explicitly concentrates on the representational aspect, thus sidelining, though not ignoring, topics such as emotions. Therefore, his theory adopts a strong constructivist flavour: the brain constructs a representation of the world which never, even in the domain of science, can claim to fully depict 'reality', however defined. Ultimately, this assertion is grounded on a Gödel-type impossibility statement (Hayek 1952: 185ff): if we aim at fully understanding the world, we also need to understand the ways and mechanisms of how our brains interact with the world. That, however, would imply that the brain must construct a model of both world and brain, which would require a degree of complexity that transcends the complexity of the brain: the brain as a system cannot construct a system that is more complex than itself. This peculiar neurophilosophical perspective clearly distinguishes Hayek from modern connectionism in neuroscience (Rust 2011) and could therefore be highly productive in considering neuroeconomics.

The most important corollary of this philosophical conclusion is that although 'mind' is not a separate substance, we can never reduce it to materialist scientific explanations (Hayek 1952: 179). We must reject Cartesian dualism, but still cannot understand human action but in mentalist terms. Neuroscience can never explain mental phenomena, only 'in principle' (Hayek 1952: 189). This is a highly original solution to the 'explanatory gap' problem in the philosophy of mind (Levine 2009) that anticipates related arguments in the philosophical literature (e.g. Lucas 1961), and it implies the impossibility of reducing psychology to neuroscience, hence addresses an important issue in current neuroeconomic debates. Psychological constructs remain important as analytical categories in explaining behaviour but cannot contradict principles of brain organization as emerging from neuroscience. As we shall see, this view is fruitful when considering questions such as whether there is a linear mapping from values to actions, or whether action continuously feeds back on values.

Hayek distinguishes between two basic types of representations of the world: 'maps' and 'models' (Hayek 1952: 112ff). A map is a more stable neuronal representation that embodies past experiences of interacting with the world in 
terms of connections between neurons and groups or structures of neurons. A model is the fluid and actual representation of the current situation within this map. Map and model work together in generating expectations about possible future consequences of situated action, i.e. as multiple trajectories of which only one eventually materializes, thus generating new information about the world, though mediated by the internal structure (Hayek 1952: 94, 118ff). The basic process that operates here is organismic homeostasis, as measured by internal standards of valuation; for the selection of realized trajectories the principle of least resistance applies (Hayek 1952: 82ff).

Hayek's connectionism has the strong implication that the information embodied in a neuronal signal never depends on its intrinsic qualities but on the position that it obtains in a certain dynamic structure (Hayek 1952: 12). The principle of holism applies, since the brain is universally interconnected, at least indirectly, such that what appears to be the same sensory input from the third-person view will never elicit the same effects; in addition, all connected structures are dynamic, and, as in the case of models, are themselves situated in action contexts (Hayek 1952: 147f). In other words, connectionism implies a strong version of individualization of the brain, both in the sense of first, that no brain is identical with other brains and second, that no process token is type-identical beyond statistical regularities, so that there can always be a wide range of variants of effects of similar external causes even within the individual (Hayek 1952: 109f).

There are important further specifications, which I summarize as follows:

- One important consequence is that the brain operates non-locally, that is, there is no unique one-to-one relationship between function and certain structures and areas of the brain. As a corollary, all structures are flexible and malleable, that is, certain structures can also adopt other and new functions, depending on circumstances (Hayek 1952: 147f, 152).

- The sensory order is a recursive hierarchical system of classifications grounded in relative frequencies of co-occurrences of neuronal activities, which are mapped on higher-level classifications that aggregate such patterns and establish more general similarities and differences (Hayek 1952: 62ff, 68ff). Therefore, there is no principled distinction between 'concrete' and 'abstract' cognitive operations in the brain, as both follow the same selectionist logic of class-formation (Hayek 1952: 108, 142).

- Learning is a fundamental process of the connectionist system proceeding in evolutionary mechanisms on two different levels, the phylogenetic and the ontogenetic (Hayek 1952: 53ff, 102f). Learning implies that the brain always operates in an interpretive mode, that is, incoming information is contextualized relative to existing maps and to the situationally constructed, dynamic models. Hence the brain does not simply adapt to the environment but is inherently creative (Hayek 1952: 122ff).

- Finally, for the evolutionary dynamics of learning, sensorimotor integration is essential, since the brain evaluates via the effects that are generated by actions, which, however, only become accessible as internal, i.e. neuronally embodied information (Hayek 1952: 18f). For this, proprioception (i.e. perception of one's own actions and internal states) is crucial; therefore the hierarchical 
organization of the neuronal network is strongly reflective, in the sense that similarities of structures are recursively built over sensorimotor feedback circuits (Hayek 1952: 90). This involves a significant role of brain-body linkages, which establishes the distinction between the internal somatic environment as compared with the external environment of the organism. The former becomes increasingly dominant, in the sense of a growing internalization of the external world in terms of its predictability via the internal representations (Hayek 1952: 80, 109).

\subsection{Hayek's views in the light of modern theories of the brain}

Hayek's theory is a general theory of the brain. Neuroscientists mostly refrain from building such 'theories of everything' in their field, in the same vein as few engage in neurophilosophy. However, in recent attempts at constructing general brain theories, there are important contributions that bear many resemblances with Hayek's. The most important case is Gerald Edelman's $(1987,2006)$ 'Neural Darwinism' that posits a selectionist model of neuronal group formation in the brain (HerrmannPillath 1992; there have been many related views, e.g. Dennett 1995; Calvin 1998). The theory starts from connectionism and, like Hayek, assumes universal connectivity across the brain in terms of complex hierarchical loops of feedbacks and re-entrant processing. Similarly, Edelman emphasizes the interaction between phylogeny and ontogeny in creating the complex multi-layered structure of the brain. Edelman also highlights the role of intra-species, population-level communication for fixing the internal dynamic structures. This is not prominent in Hayek's Sensory Order but plays a significant role in his mature theories of cultural evolution (Hayek 1979). I come back to this in the final section.

The comparison with Edelman also allows for further clarification of the meaning of 'evolutionary'. Edelman explicitly refers to the analytical paradigm of natural selection for understanding evolutionary dynamics. This has raised the question how far the Neodarwinian synthesis of genetics and Darwinian evolution applies, such as in identifying formal homologies to concepts such as replication, phenotype and so on (Fernando et al. 2012). Hayek's evolutionary approach does not hinge on Darwinian specifics, however. In fact, as Austrian economics commentators have highlighted, his view has much in common with his evolutionary views on markets, especially the emphasis on competition, radical uncertainty, and the role of contextualized and local knowledge, as opposed to rational design and centralized control (Di Iorio 2010). This broader perspective is reflected in his philosophical evaluation of the neuroscientific theory, which also defines a difference from Edelman, and which we outlined previously in referring to the 'explanatory gap'.

Another important recent brain theory is Karl Friston's thermodynamic approach that almost reads like a formalization of Hayek's observation that the brain can only adapt to the world via the indirect processing of internal mappings and evaluations, subject to general evaluative benchmarks defined by organismic homeostasis. As has been suggested by Friston and collaborators (Friston 2010; Friston et al. 2010; Solms and Friston 2018), the only way to 
adjust internal representations to the external world is by correcting internal states of disequilibrium that result from predictive failures of acting in the external world; these remain purely neurobiological states only causally related to 'hidden states' of the world. In addition, the recognition of these predictive failures is only mediated by internal representations, too - there is no independent external check. That means, as Friston emphasizes, the brain constructs internal maps of the world which simultaneously generate perceptions qua hypotheses about those hidden states (all 'sensory data' are fallible hypotheses) and predictions about the effects of actions that are ultimately only being perceivable as changes in internal disequilibrium. This is an evolutionary process of statistical optimization in a highly modularized structure which allows for comparison and mutual adjustment of perceptions across those various structures. Hayek anticipates these basic ideas, especially in his references to the emerging General Systems Theory of his day.

Finally, as is true for connectionism in general, Hayek's theory is compatible with many approaches in the field of computational neuroscience which study neural network formation and dynamics. This applies to more specific evolutionary modelling approaches, such as the dynamic models of action selection (Prescott et al. 2007; Verschure 2016) which can be directly referred to neuroeconomics. Therefore, in sum I conclude that many of Hayek's basic ideas remain relevant in the context of modern neuroscience. However, so far researchers working on the cross-disciplinary integration of economics, neurosciences and psychology have ignored Hayek's foundational contribution. In the next section, I narrow down my discussion to the study of choice and the question of whether Hayekian neurophilosophy is the canvas on which evolutionary mechanisms of choice can be conceived as alternatives to the established economic models of choice.

\section{The evolutionary alternative to paradigmatic models of choice in neuroeconomics and behavioural economics}

\subsection{The good-based model of choice}

One of the most influential models in current neuroeconomics is Padoa-Schioppa's (2011) 'good-based model', which bears many resemblances to Glimcher's (2011) framework that has earned the label of 'neuroclassical' (Camerer 2013). This has been confronted recently with an evolutionary alternative programmatically articulated by Hunt and Hayden (2017). Indeed, some established alternative approaches in neuroeconomics have an affinity to an evolutionary perspective if choice is framed in terms of reinforcement learning under uncertainty: e.g. the drift-diffusion model assumes that individuals continuously compare values of alternatives in a stochastic setting, and opt for an alternative once a threshold is surpassed for one alternative (Fehr and Rangel 2011; Padoa-Schioppa and Conen 2017 distinguish this clearly from the good-based model).

The good-based model centres on 'subjective value', which, as most neuroeconomists agree, is expected to be the empirical counterpart to 'utility' in the standard economic model. However, the good-based model (differently from Glimcher's) operates without making a two-level mapping explicit: in this sense, 
it leads to reductive elimination of utility. Subjective value is situationally constructed, which superficially seems to correspond to Hayek's conception of a 'model'. This view is strongly influenced by the empirical work on dopaminergic circuits as driving choices: the situational factor looms large here because what determines relative subjective value is driven by deviation of realized from expected conditions of choice. This differs radically from Hayek's approach in which the embodiment of past experience in neuronal structure is a core feature.

In contemporary debates about the dopamine-based reward system, there is an alternative interpretation championed by Berridge (2009; overview in Gazzaniga et al. 2014: 530ff) that differentiates between 'wanting', 'liking' and 'learning' as separate types of processes determining choices, with dopaminergic circuits only involving the 'wanting' part. This would allow for establishing a precise relationship between the Hayekian concepts of 'map' and 'model': the model would correspond to the situational emergence of wanting, whereas the map reflects memorized structures of valuation. The good-based model reduces learning to the situational adaptation in the first place, whereas the Hayekian view emphasizes learning in the longer run via structural stabilization of neuronal connections, including specieslevel learning via genetically programmed basal connectivities.

The peculiar view on learning in the good-based model results from its strictly linear construction. That means, as in the economic model, subjective value drives choice, and there is no feedback from action to subjective value, unless one considers an entirely new causal sequence of choice. Padoa-Schioppa explicity rejects reference to sensorimotor feedback circuits, which is deemed necessary to establish a neat analytical boundary between valuation, choice and action. Further, a central feature of the good-based model is strong localization of subjective value, even down to the level of single neurons or smaller aggregates of neurons.

In this sense, the construction of subjective value is not the main aim of the approach, which corresponds to the foundational notion of subjectivity in economics, implying that subjective value is not explained in any other terms. Accordingly, what counts most is whether one can show that the neuronally determined mechanisms of choice match with basic economic axioms of choice, such as transitivity and menu invariance, in this sense also staying in the tradition of revealed preference interpretations of the utility function. However, the need for explaining the emergence of subjective value remains important in an empirically grounded theory of choice. Interestingly, Rustichini and Padoa-Schioppa (2015) build on a selectionist neuronal network model to tackle this question. This step is ambivalent, though, as Hunt and Hayden (2017) refer to the same approach as suggesting an evolutionary alternative to the good-based model. In other words, the good-based model just neutralizes the evolutionary alternative, confining learning to the formation of value, only to follow economics in declaring this question as marginal to understanding the mechanism of choice.

To summarize, the hallmark of the good-based model is to identify and strictly localize a mechanism of economic choice that is formally homologous to the economic model, equates subjective value and utility, and therefore eventually eliminates the economic model by reduction, while also transforming it into a falsifiable hypothesis. Evolutionary mechanisms may be relevant for explaining the emergence of subjective value, but not for choice. 


\subsection{The alternative: evolutionary mechanism of choice}

The generic evolutionary approach argues on different analytical levels (compare Hull et al. 2001), of which I will mainly consider the first and the third, for reasons of limited space (for an exemplary review of pertinent evolutionary approaches to development, see Hadders-Algra 2018):

First, can we deduce generalized mechanisms of choice based on evolutionary 'first principles' which refer to the phylogeny of the human brain?

Second, can we approach development and learning as an evolutionary process? Third, can we approach action selection in an evolutionary model of brain processes?

The importance of the first point comes to the fore if we consider that the notion of subjective value in the good-based model is explicitly representational and does not include any action component. In comparison, the evolutionary argument on phylogeny refers to the ideal-typical patch selection scenario and foraging logic in early hominid scavenging, which suggests a continuous process of choice under uncertainty, including both uncertainty about future benefits from foraging and other risks, such as predation (Cisek 2007, 2012). Accordingly, it is suggested that valuation is enacted by sensorimotor circuits, which directly corresponds to Hayek's view.

This evolutionary argument converges with grounded cognition theories in the cognitive sciences that claim that there is no representation without integrating sensory and motor systems (Barsalou 2008). This would radically question the idea that there is a linear sequence between subjective value and action, and instead posits that action continuously changes subjective value, or, even stronger, that there is no value without action (a position that has been developed by Ariely and collaborators in various contributions, e.g. Ariely and Norton 2007). In Hayek's theory, this corresponds to the map/model dichotomy: choice is determined by models, and models evolve during enacting valuations and engaging in proprioception of sensorimotor feedback loops.

Let me introduce a scenario to clarify the down-to-earth implications (for the wider theoretical context in grounded cognition theory, see Papies et al. 2020). The standard neuroeconomic model mostly focuses on simple choices among clearly defined alternatives, such as choosing among different items of food. Imagine a man and a woman sitting at a bar, ordering and drinking cocktails. We can approach this as a choice between one variant of cocktail or another, or other kinds of drink. However, there is the problem of how to define what is a unit of 'action' here, and even what is the action all about. One is certainly ordering the cocktail, i.e. choosing among alternatives. But we can also further dissect the ensuing action, such as considering the sequences of sipping the drink. This involves choices over the quantity of each sip, the pace of sipping, and possibly other complementary actions, such as proposing toasts. Whereas the choice between types of drinks fits squarely in the good-based model, the more disaggregate view speaks in favour of an evolutionary approach, because there is a continuous feedback between actions and valuations, and because the 
model, in the Hayekian sense, co-evolves with the situation. This can include major interpretive shifts: but these happen on a higher level than the single choice, such that the single act of choice seems inextricably enmeshed in multi-level causal relationships. Assume, for example, that the conversation takes a turn that activates erotic expectations, which might directly affect the pace of sipping or may even alter the neurophysiological effects of the alcohol in the cocktails.

In sum, first principles thinking suggests an evolutionary logic of continuous shifting of contextualized decisions, which strongly involve sensorimotor feedbacks. This argument relates to the role of memory in establishing context, which has been increasingly recognized even by protagonists of the neuroeconomic standard model (Louie et al. 2015), and probably the relationship between memory and fundamental processes in action generation, especially attention (Puglisi et al. 2017), which is also strongly emphasized by Hayek (1952: 139ff).

The general idea starts from the observation that the computational needs for establishing subjective value based only on the current setting of action seem to be exacting (Shohamy and Daw 2015) (imagine, in the bar example, a recurrent full-scale, fast and entirely new construction of subjective value in a tightly packed sequence of complete cycles of choice). Instead, a cost-saving procedure would be based on precedent. That means, cues would suffice to generate a memorized model which then guides choices, without considering all potential information inherent in the current situation. In a Hayekian view, this would imply that there is a range of available potential models that compete over action control, until one is selected as most appropriate according to internal evaluative standards. In our bar example, there are competing potential models of the situation, and cues are continuously generated and evaluated, until actions converge on one model. This model determines, for example, whether a second cocktail is ordered or not. To a certain extent, this matches with the strong subjectivist flavour of the good-based model but goes beyond it in emphasizing the role of memorized models and the selectionist dynamics.

There are various approaches in the neurosciences and psychology which endorse such an evolutionary approach to mechanisms of choice. For example, there is the 'event files' concept, according to which action preparation happens over competing event files stored in memory (Hommel and Wiers 2017). The selection is not directly driven by objective environmental factors, as there is a strong role of motivation and attention: what operates as a cue is not given, but depends on certain predispositions shaped by attention, and this in turn by motivational forces. The cue does not directly determine valuation, but model selection, and the model determines valuation. Cisek applies the Gibsonian term 'affordance' to grasp this interaction between agent and environment conceptually (Pezzulo and Cisek 2016). One advantage of this view compared with the good-based model is that it allows for a wider range of types of choices beyond the narrow scope of picking among alternatives in the short term (Ross 2014: 226ff).

Evolutionary mechanisms may be especially powerful in social interaction where complexity and uncertainty loom large, and not only perception of means, but also goals may shift instantaneously (Verschure 2016) (in our bar example, what counts most is not the object of choice, the cocktail, but how the man and the woman converge on a shared perception of the scene; Redcay and Schilbach 2019). This 
requires a strong capacity for meta-level action control in which goals and ends are contextualized simultaneously (Foxall 2016). That means, two types of mechanisms work together in a hierarchically ordered system: one is the generation of action variants, the other is the identification and transient fixation of the internal selective environment that mirrors the perceived external situation. The latter process must also be conceived in terms of an evolutionary mechanism, since the interpretation of context can switch instantaneously depending on which environmental cues arrive: Northoff (2016) speaks of the interaction between 'sociocultural statistics' of contexts and 'natural statistics' of stimuli.

In sum, the evolutionary approach allows for a much richer analysis of choice dynamics compared with the rather mechanistic good-based model, and, as argued already by Hayek (1952: 122) takes account of the creativity of choice. In this broader framework, it is also easier to integrate more complex choices, which are so far not covered at all by the 'neuroclassical' model, and more complex determinants such as emotions (Camerer 2013).

\subsection{Beyond dual systems}

As pointed out in the first section, the canonical model of choice in neuroeconomics is in direct tension with the canonical model in behavioural economics: one of the most influential ideas in behavioural economics is the dual systems or dual process approach which is essential for systematically explaining deviations from standards of rationality as established in formal frameworks of economics, such as in optimization models or game theory (overview in Alós-Ferrer and Strack 2014; championed by both Nobel laureates in the field, Kahneman 2011 and Thaler 2016). This is not the place to delve into details, but I wish to concentrate on the question whether and how the evolutionary approach calls dual process theories into question, while considering neuroscientific evidence (for a more detailed and specialized discussion, see Herrmann-Pillath 2019). As a corollary, I ask what Hayekian neurophilosophy implies for grounding behavioural economics in neuroscience, again with a focus on mechanisms of choice.

Protagonists of the dual process models are careful in suggesting neural embodiments, yet there is clearly the need to demonstrate how alleged systemic differences correspond to brain structures (Kahneman 2011: 366; Brocas and Carrillo 2014; these efforts were launched with the seminal paper by Trepel et al. 2005). On the surface, this seems obvious, as classical expositions distinguish between two levels - one associated with notions such as 'fast', 'unconscious', 'affective' or 'automatic processing', the other with their polar opposites - and place a strong emphasis on symbolic representation and propositional logic: Apparently, this matches with macro-structural oppositions such as between the prefrontal cortex and other parts of the brain, e.g. the limbic system.

Hayek argues explicitly against any attempts to establish more principled divisions among cognitive capacities and functions in the brain, since in his view all cognitive operations are embodied in systems of neuronal categorization and topological structure, and all involve proprioception of effects of actions, both in the internal (somatic) and the external environment. In addition, he also presents a concept of consciousness that is surprisingly close to most recent advances in psychology and 
the neurosciences (Hayek 1952: 134ff). He describes consciousness as the capacity 'to give an account' or 'take account' of actions and other behavioural phenomena. Most significantly, this includes communication with others, hence essentially relies on symbolic media shared in groups of individuals. Although Hayek did not further explore this, his position is akin to radical critiques of standards of rationality as deployed in economic uses of the dual systems model (Mercier and Sperber 2018). If conscious, deliberate and argumentative thinking mainly serves the goal of convincing others of one's own valuations, reasons for action or justifying behaviour, we cannot project third-person criteria of objective representation on what we might even still approach as the 'rational system'. In other words, even if we maintained a systemic dualism, the fundamental purpose of human rationality ('system 2') would be different from claiming a convergence to a third-person objective perspective on the world. Ultimately, this argument relies on an evolutionary explanation in phylogenetic terms, i.e. asking for the evolved purpose of human rationality (for an early exposition of that view, see Herrmann-Pillath 1994).

The neuroscience literature has undermined dual process theories mainly in two ways, as far as the more specific question of mechanisms of choice is concerned (for more detail, see Herrmann-Pillath 2019). One is that relative to the actions taken, the speed of interactions across brain areas which are respectively supposed to identify with the two systems is fast enough to enable any kind of interaction between the systems, unless we consider purely visceral responses to stimuli (for a seminal study, see Cunningham and Zelazo 2007). In other words, even if we accept the dual systems distinction, relative to the speed of action in the external environment, interaction between the systems would be faster anyway. Going back to the bar example, even choosing when to take the next sip is slow enough to engage all potentially relevant areas of the brain. In particular, the simultaneous shifting of means and goals can alter decision frames almost instantaneously, thus also affecting what would count as 'rational' depending on context (Wiers et al. 2020). For example, the woman at the bar may first put health considerations high on her agenda in controlling decisions about drinking, but may shift to entertainment goals swiftly, depending on the interaction with the man. In other words, dual process theories often implicitly (or, in applications on nudging, explicitly) introduce the observer's behavioural standards in judging the goal-specific 'rationality' of displayed behaviour (Sugden 2018 speaks of the 'inner rational agent' projected on the real agent, a variant of the 'homunculus' à la Dennett 1995).

The other argument is that the dual view does not pay enough respect to the complex hierarchical structure of the brain beyond apparent functional division among locations in the three-dimensional brain mass. This partly reflects a certain naiveté in reifying functions, such as memory or attention, following the uses of the terms in ordinary language. However, it is well established that such generic functions involve second-level networks of brain areas, and even thirdlevel interactions between those networks, which often include all areas supposedly assigned differentially to the dual processes. For example, memory is a multi-faceted and distributed phenomenon with many functions, locations and types of processes, and they play together in supporting human action. The question is how we could take proper account of this complexity in a dual systems framework. An intriguing question is how the brain creates and 
maintains the 'Self that does the choosing, which remains a deep mystery in the standard model of economic choice (Davis 2003, 2010): with the discovery of the Default Mode Network, neuroscientists realized that the brain is most active and consumes most energy in its resting state, when it is mostly focused on its internal processes, and that action implementation goes along with reducing activity levels (Raichle 2015). The DMN is a paramount example of complex mappings across many brain areas (Li et al. 2014) and probably is the arena where the evolutionary dynamics of decisions unfolds and is grounded, while constructing a core of personal identity in the flow of choices. More recently, Redcay and Schilbach (2019) suggest a 'mentalizing network' that is crucial for enabling and orienting social interaction in continuously evolving contexts.

This complexity comes to the fore when considering phenomena that, on first sight, may involve only one process, such as empathy, often simplistically related to 'emotions'. Empathy is of interest here, because in early stages of neuroeconomics, the direct impact of externally administered hormones on empathic stances received much attention (e.g. Zak et al. 2007). But today we know that empathy is a complex phenomenon that involves both bottom-up and top-down processes (Singer and Lamm 2009; Decety 2015), even to the degree that apparently fixed hormonal mechanisms become entirely dependent on context: oxytocin can increase or decrease trust, depending on the identification of ingroup/outgroup boundaries mainly via symbolic operations (Declerck et al. 2010, Declerck 2020). This clearly matches with Hayek's views, since bottom-up and topdown processes are integrated in complex systems of categorizing agents and actions, and cannot be reasonably dissociated into two different types of processes - or even assign empathy only to one, unless we also dissect empathy into different types of empathic behaviours, which, however, begs the question how to distinguish these types empirically (Decety and Yoder 2016).

There are other troubles with the dual systems view: one general critique is that it raises logical tensions, if not paradoxes in how the brain first 'chooses' which process should be realized, which necessarily introduces a meta-level beyond the duality (Foxall 2016). This fundamental point is in the spirit of Hayek's emphasis on the philosophical difficulties in dealing with reflexivity of the brain. Hence, the dual systems view appears to introduce a false juxtaposition between 'reflection' as the supposedly essential form of rational behaviour and action (a form of a more general mind-body duality), and non-reflexive behaviour (as in the classical exposition by Strack and Deutsch 2004). Putting more flesh on the bones of this abstract point, attention and motivation seem to be powerful forces that drive the selection of types and responses - in the sense of creating 'preparedness', which itself does not easily fit into the systemic duality (Spunt 2015; Wiers and Gladwin 2017). Preparedness is what transpires from Hayek's duality of map and model, too.

This view receives further support if one shifts attention away from the logical structure of propositions to their semantics: the dual systems view tends to overemphasize syntactical, logical and mathematical modes of thought, while downplaying other modes and functions of language (i.e. defines symbolic processing in an amodal way, Niedenthal et al. 2005). This involves two aspects.

The first is that according to modern views in psycholinguistics (aptly summarized by Pinker 2007), even abstract concepts are based on integrating 
the action dimension, in the sense that meanings are embodied in sensorimotor circuits, as also seminally suggested by grounded cognition theorists and in theories of metaphor as a fundamental cognitive operation enabling symbolic mediation (Barsalou 2008; Lakoff 2019).

The other is that there is strong empirical evidence that our assignment of actions to the reflective or the non-reflective domain depends on the media of representation and on the developmental history of a person. One observation refers to the famous experiments on social intelligence, where the capability of conducting correct logical reasoning depends on whether the problem is presented in an abstract numerical way or as a vignette involving discovery of cheating (Cosmides and Tooby 2005). There are many related observations, which present a strong case for intuitive logic as opposed to reflective or propositional logic, though the observer may represent both in the same logical structure in the third-person perspective, such as in probability calculus (Handley and Trippas 2015). This also strengthens the case against simple orthogonal oppositions that would converge in two systemic domains (Spunt 2015). For example, an apparently automatic action may be embedded in simultaneous reflective feedback loops which embed the action in a larger pattern of action: a skilled musician may move fingers without considering the actual movements, but has a moving target in connecting these actions with the following ones in one larger pattern, which remains fully reflected while playing. Such interdependencies are established by fundamental processes such as attention.

In sum, the Hayekian perspective, if evaluating rich neuroscientific evidence, presents a strong case against the dual systems view which currently dominates behavioural economics. The evolutionary view, though much more complex and dynamic than the dual systems approach, still maintains the idea of a unitary human agent. This is desirable also for normative reasons, as there is the danger that the scientist assumes the authority of defining what the 'better self wants, thus adopting an authoritarian stance in applying behavioural economics insights in policy design (Harrison and Ross 2017; Sugden 2018). Tellingly, this observation evokes the strong liberal political instincts of Hayek.

\section{Outlook}

One of the advantages of approaching choice in evolutionary terms is that it recognizes the complexity of the brain and avoids false claims of localization and specialization that often characterize what Don Ross (2014) calls 'behavioural economics in the scanner'. At the same time, it also puts micro-level empirical research into context, thus avoiding false extensions of valuable insights on one mechanism of choice across all types of decisions. In this sense, it is a regulatory set of ideas that goes beyond what is empirically vindicated, but that also applies for competing theories. In comparison, adopting evolutionary thinking as a regulatory methodology may make theorists less prone to pursuing tracks of research that eventually lead into blind alleys, such as overextending localization claims.

For economics, the most important consequence of the evolutionary approach lies partly beyond the scope of Hayek's original contribution in the Sensory Order, though is an essential part of his later intellectual development (e.g. 
Hayek 1979). In this paper, I have concentrated on evolutionary mechanisms of choice, and this is where the Sensory Order is directly relevant. But the evolutionary perspective in general is much broader, which is also reflected in Hayek's oeuvre (Vanberg 2018). This matches with the current situation in economics, where the naturalistic turn has also generated another strand of evolutionary thinking in the context of experimental economics, and which emphasizes levels of analysis above that of the individual, such as the institutional and the cultural, as shaping rational choice - dubbed 'ecological rationality' by Vernon Smith (2004). This points to another deplorable loss of theoretical continuity in contemporary economics: modern behavioural economics mostly marginalizes the first generation of behavioural economics, which strongly influenced Vernon Smith, and was contemporaneous with Hayek's work (Davis 2010). The towering figure in this tradition is Herbert Simon: Hayek scholars have emphasized the strong affinities between Hayek's and Simon's theories on individual behaviour (Frantz 2013; Marsh 2013).

In the Hayekian framework, it is straightforward integrating these two levels of naturalizing economics into one evolutionary paradigm. This point also transpired in the Austrian economics debates over the relationship between the Sensory Order and Hayek's non-reductionist views on cultural and institutional evolution: the Sensory Order offers a comprehensive foundation for understanding the human capacity to follow rules and to harness social interactions and structures in accumulating knowledge in society, and shows how different levels of learning interact, without individual embodiment also implying individual epistemic control and design (Di Iorio 2010; Lindemans 2011).

Recognizing the role of culture and human sociality as being fundamental for understanding the human brain, in distinction from all non-human organisms, and hence for economic behaviour, is increasingly a concern in the neurosciences (dubbed the 'social brain' hypothesis, Alós-Ferrer 2018, going back to seminal contributions such as Frith 2007). In his later work, Hayek greatly emphasized the interaction between biological, cultural and individual factors in driving human behaviour. This interaction is the topic of new subdisciplines in the neurosciences, especially cultural neuroscience and social neuroscience (Han et al. 2013; Hyde et al. 2015), or, just budding, 'social neuroeconomics' (Harbecke and Herrmann-Pillath 2020). The methodological consequences of this have been already drawn by Don Ross in his elaborations on neuroeconomic methodology, distinguishing between a 'molecular' and a 'molar' approach (Ross 2008, 2012). The central point is that neuroeconomics is possible in terms of non-reductive research methodology which combines basal neurophysiological mechanisms with external patterns in the social context, especially symbolic media (which would be the 'molar' as opposed to reductionistic 'molecular' approaches). We have already met a powerful example: the interaction between bottom-up and top-down processes in empathy. In a most general way, this refers to the contextualization of all neurophysiological mechanisms, thus introducing a high degree of flexibility, malleability and indeterminacy between mechanisms and behavioural outcomes (Alós-Ferrer 2018). However, these only appear indeterminate if we do not include context as a causal factor, i.e. if we are pursuing a false methodology of reductionism (Takahashi and Egashira 2013; Herrmann-Pillath 2020). 
As Ross (2014: 281ff) has emphasized, the important consequence for economics is that in cross-disciplinary collaboration and integration, psychology would no longer be the prime choice, but rather sociology and social psychology combined with neuroscience. Behavioural economics pursues an overly individualistic research strategy, whereas a fully fledged evolutionary approach would include macropatterns in context, such as the transmission of culture shared in a population of agents. The core empirical phenomenon is development and socialization, which can be approached as an evolutionary process, too, but was not treated in this paper.

In comparison, here is a catch with the neuroclassical approach (compare Bernheim 2009). If neuroeconomics can really succeed in reducing the economic model to neuroscience, would that matter at all for economists? Clearly, no. They could feel satisfied that their model can be grounded empirically, but would just continue with using their own model, if only for conceptual parsimony. You don't need quantum mechanics to design a bridge according to the physical constraints that matter on that macroscopic level of action. The same is not true for the dual systems model, but again, implicitly this maintains reference to the standards of economic rationality as a benchmark for judging deviations. Ultimately, most of contemporary behavioural economics aims at creating an economic world in which standard rationality reigns. Therefore, for envisaging a truly innovative approach to integrating neurosciences and economics, the evolutionary view, going back to Hayek's seminal work, is most promising.

Acknowledgements. I am deeply indebted to Frédéric Basso who, a decade ago, shared a book manuscript in French with me that he co-authored with Olivier Oullier, Le Corps and les Prix: Esquisse d'une Théorie Sensorielle de la Valeur. Alas, that manuscript was never published. I received many stimulating ideas from reading it, which only today start to bear fruit (of course, our conversation continues to fertilize my orchard). Reinout Wiers suggested crucial readings to me (including his own important ongoing work). I am grateful to two anonymous reviewers who critically contributed to substantial improvements of earlier versions of this paper.

Financial support. This work was funded by ERA-NET NEURON in the context of the INSOSCI project 'The integration of cross-disciplinary research in neuroscience and social science - a methodological case study on economic policies and the neuroscience of agency', Grant number 01GP1625.

\section{References}

Alós-Ferrer C. 2018. A review essay on social neuroscience: can research on the social brain and economics inform each other? Journal of Economic Literature 56, 234-264.

Alós-Ferrer C. and F. Strack 2014. From dual processes to multiple selves: implications for economic behaviour. Journal of Economic Psychology 41, 1-11.

Ariely D. and M.I. Norton. 2007. How actions create - not just reveal - preferences. Trends in Cognitive Science 12, 13-16.

Barsalou L.W. 2008. Grounded cognition. Annual Review of Psychology 59, 617-645.

Basso F., L. Guillou and O. Oullier 2010. Embodied entrepreneurship: a sensory theory of value. In Neuroeconomics and the Firm, ed. A.A. Stanton, D.M. Day and I.M. Welpe, 217-234. Cheltenham: Edward Elgar.

Bernheim B.D. 2009. The psychology and neurobiology of judgment and decision making: what's in it for economists? In Neuroeconomics: Decision Making and the Brain, ed. P.W. Glimcher, C.F. Camerer, E. Fehr and R.A. Poldrack, 115-126. Amsterdam: Elsevier.

Berridge K.C. 2009. 'Liking' and 'wanting' food rewards: brain substrates and roles in eating disorders. Physiology and Behavior 97, 537-550. 
Bickle J., P. Mandik and A. Landreth 2019. The philosophy of neuroscience. In The Stanford Encyclopedia of Philosophy (Fall 2019 Edition), ed. E.N. Zalta. <https://plato.stanford.edu/archives/fall2019/entries/ neuroscience/>.

Boettke P., W.Z. Caceres and A. Martin 2013. Error is obvious, coordination is the puzzle. In Hayek and Behavioral Economics, ed. R. Frantz and R. Leeson, 90-110. Basingstoke: Palgrave Macmillan.

Bossaerts P. and C. Murawski 2015. From behavioural economics to neuroeconomics to decision neuroscience: the ascent of biology in research on human decision making. Current Opinion in Behavioral Sciences 5, 37-42.

Brocas I. and J.D. Carrillo 2014. Dual-process theories of decision-making: a selective survey. Journal of Economic Psychology 41, 45-54.

Buckner C. and J. Garson 2019. Connectionism. In The Stanford Encyclopedia of Philosophy (Fall 2019 Edition), ed. E.N. Zalta. https://plato.stanford.edu/archives/fall2019/entries/connectionism/.

Butos W.N., ed. 2010. The Social Science of Hayek's 'The Sensory Order' (Advances in Austrian Economics, Vol. 13). Bingley: Emerald Publishing.

Butos W.N. and T.J. McQuade 2015. The Sensory Order, neuroeconomics, and Austrian economics. In The Oxford Handbook of Austrian Economics, ed. P.J. Boettke and C.J. Coyne, 612-641. Oxford: Oxford University Press.

Calvin W.H. 1998. Competing for consciousness: a Darwinian mechanism as an appropriate level of explanation. Journal of Consciousness Studies 5, 389-404.

Camerer C. 2013. A review essay about Foundations of Neuroeconomic Analysis by Paul Glimcher. Journal of Economic Literature 51, 1155-1184.

Camerer C., G. Loewenstein and D. Prelec 2005. Neuroeconomics: how neuroscience can inform economics. Journal of Economic Literature 43, 9-64.

Churchland P.S. 1989. Neurophilosophy: Toward a Unified Science of the Mind-Brain. Cambridge, MA: MIT Press.

Cisek P. 2007. Cortical mechanisms of action selection: the affordance competition hypothesis. Philosophical Transactions of the Royal Society B: Biological Sciences 362, 1585-1599.

Cisek P. 2012. Making decisions through a distributed consensus. Current Opinion in Neurobiology 22, 927-936.

Cosmides L. and J. Tooby 2005. Neurocognitive adaptations designed for social exchange. In The Handbook of Evolutionary Psychology, ed. D.M. Buss, 584-628. Hoboken, NJ: Wiley.

Craver C. 2007. Explaining the Brain. Mechanisms and the Mosaic Unity of the Neurosciences. New York, NY: Oxford University Press.

Cunningham W.A. and P.D. Zelazo 2007. Attitudes and evaluations: a social cognitive neuroscience perspective. Trends in Cognitive Sciences 11, 97-104.

Davis J.B. 2003. The Theory of the Individual in Economics: Identity and Value. London: Routledge.

Davis J.B. 2010. Individuals and Identity in Economics. Cambridge: Cambridge University Press.

Decety J. 2015. The neural pathways, development and functions of empathy. Current Opinion in Behavioral Sciences 3, 1-6.

Decety J. and K.Y. Yoder 2016. Empathy and motivation for justice: cognitive empathy and concern, but not emotional empathy, predict sensitivity to injustice for others. Social Neuroscience 11, 1-14.

Declerck C. 2020. Neuroeconomics of cooperation heuristics: the role of incentives, social cues, and hormones. In Social Neuroeconomics: Mechanistic Integration of the Neurosciences and the Social Sciences, ed. J. Harbecke and C. Herrmann-Pillath, 77-96. London: Routledge.

Declerck C., C. Boone and T. Kiyonari 2010. Oxytocin and cooperation under uncertainty: the moderating influence of incentives and social information. Hormones and Behavior 57, 368-374.

Dennett D.C. 1995. Darwin's Dangerous Idea: Evolution and the Meanings of Life. New York, NY: Simon \& Schuster.

Di Iorio F. 2010. The Sensory Order and the neurophysiological basis of methodological individualism. In The Social Science of Hayek's 'The Sensory Order' (Advances in Austrian Economics, Vol. 13), ed. W.T. Butos, 179-209. Bingley: Emerald.

Edelman G.M. 1987. Neural Darwinism: The Theory of Neuronal Group Selection. New York, NY: Basic Books.

Edelman G.M. 2006. Second Nature: Brain Science and Human Knowledge. New Haven, CT: Yale University Press. 
Fehr E. and A. Rangel. 2011. Neuroeconomic foundations of economic choice - recent advances. Journal of Economic Perspectives 25, 3-30.

Fernando C., E. Szathmáry and P. Husbands 2012. Selectionist and evolutionary approaches to brain function: a critical appraisal. Frontiers in Computational Neuroscience 6. https://doi.org/10.3389/ fncom.2012.00024.

Foxall G.R. 2016. Metacognitive control of categorial neurobehavioral decision systems. Frontiers in Psychology 7. https://doi.org/10.3389/fpsyg.2016.00170.

Frantz R. 2013. Frederick Hayek's behavioural economics in historical context. In Hayek and Behavioral Economics, ed. R. Frantz and R. Leeson, 1-34, Basingstoke: Palgrave Macmillan.

Frantz R. and R. Leeson, ed. 2013. Hayek and Behavioral Economics. Basingstoke: Palgrave Macmillan.

Friston K. 2010. The free-energy principle: A unified brain theory. Nature Reviews Neuroscience, doi: 10. 1038/nrn2787.

Friston K.J., J. Daunizeau, J. Kilner and S.J. Kiebel 2010. Action and behavior: a free-energy formulation. Biological Cybernetics. doi: 10.1007/s00422-010-0364-z.

Frith C. 2007. The social brain? Philosophical Transactions of the Royal Society B 362, 671-678.

Fuster J.M. 2011. Hayek in today's cognitive neuroscience. In Hayek in Mind: Hayek's Philosophical Psychology (Advances in Austrian Economics, Vol. 15), ed. L. Marsh, 3-11. Bingley: Emerald.

Gazzaniga M.S., R.B. Ivry and G.R. Mangun 2014. Cognitive Neuroscience: The Biology of the Mind. 4th edition. New York, NY: WW Norton.

Glimcher P.W. 2011. Foundations of Neuroeconomic Analysis. Oxford: Oxford University Press.

Gul F. and W. Pesendorfer 2008. The case for mindless economics. In The Foundations of Positive and Normative Economics, ed. A. Caplin and A. Schotter, 3-41. Oxford: Oxford University Press.

Hadders-Algra M. 2018. Early human motor development: from variation to the ability to vary and adapt. Neuroscience and Biobehavioral Reviews 90, 411-427.

Han S., G. Northoff, K. Vogeley, B.E. Wexler, S. Kitayama and M.E.W. Varnum 2013. A cultural neuroscience approach to the biosocial nature of the human brain. Annual Review of Psychology 64, 335-359.

Handley S.J. and D. Trippas 2015. Dual processes and the interplay between knowledge and structure: a new parallel processing model. Psychology of Learning and Motivation 62, 33-58.

Harbecke J. and C. Herrmann-Pillath, ed. 2020. Social Neureconomics: Mechanistic Integration of the Neurosciences and the Social Sciences. London: Routledge.

Harrison, G.W. and D. Ross 2017. The empirical adequacy of cumulative prospect theory and its implications for normative assessment. Journal of Economic Methodology 24, 150-165.

Hayek F.A. von 1952. The Sensory Order. An Inquiry into the Foundations of Theoretical Psychology. Chicago, IL: University of Chicago Press.

Hayek F.A. von 1979. Law, Legislation and Liberty: A New Statement of the Liberal Principles of Justice and Political Economy. Volume 3: The Political Order of a Free People. Chicago, IL: University of Chicago Press.

Hebb D.O. 1949. The Organization of Behavior: A Neuropsychological Theory. New York, NY: John Wiley \& Sons.

Herrmann-Pillath C. 1992. The brain, its sensory order and the evolutionary concept of mind. On Hayek's contribution to evolutionary epistemology. Journal of Social and Biological Structures 15, 145-187.

Herrmann-Pillath C. 1994. Evolutionary rationality, "homo economicus" and the foundations of social order. Journal of Social and Evolutionary Systems 17, 41-70.

Herrmann-Pillath C. 2019. From dual systems to dual function: rethinking methodological foundations of behavioural economics. Economics and Philosophy 35, 403-422.

Herrmann-Pillath C. 2020. Mechanistic integration of social sciences and neurosciences: context and causality in social neuroeconomics. In Social Neuroeconomics: Mechanistic Integration of the Neurosciences and the Social Sciences, ed. J. Harbecke and C. Herrmann-Pillath, 47-73. London: Routledge.

Hommel B. and R.W. Wiers. 2017. Towards a unitary approach to human action control. Trends in Cognitive Sciences 21, 940-949.

Hull D.L., R.E. Langman, E. Rodney and S.S. Glenn. 2001. A general account of selection: biology, immunology and behaviour. Behavioral and Brain Sciences 24, 511-573.

Hunt L.T. and B.Y. Hayden. 2017. A distributed, hierarchical and recurrent framework for reward-based choice. Nature Reviews Neuroscience 18, 172-182. 
Hyde L.W., S. Tompson, J.D. Creswell and E.B. Falk. 2015. Cultural neuroscience: new directions as the field matures. What do cultural neuroscience findings mean? Culture and Brain 3, 75-92.

Kable J.W and P.W. Glimcher 2007. The neural correlates of subjective value during intertemporal choice. Nature Neuroscience 10, 1625.

Kahneman D. 2011. Thinking, Fast and Slow. London: Penguin Books.

Lakoff G. 2019. Ten Lectures on Cognitive Linguistics. Leiden: Brill. https://doi.org/10.1163/9789004325302.

Levine J. 2009. The explanatory gap. In The Oxford Handbook of Philosophy of Mind, ed. B.P. McLaughlin, A. Beckermann and S. Walter, 281-291. Oxford: Clarendon Press.

Li, W., X. Mai and C. Liu 2014. The default mode network and social understanding of others: what do brain connectivity studies tell us. Frontiers in Human Neuroscience 8. https://doi.org/10.3389/fnhum. 2014.00074 .

Lindemans J.W. 2011. Hayek's post-positivist empiricism: experience beyond sensation. In Hayek in Mind: Hayek's Philosophical Psychology (Advances in Austrian Economics, Vol. 15), ed. L. Marsh, 143-170. Bingley: Emerald.

Louie K., P.W. Glimcher and R. Webb 2015. Adaptive neural coding: from biological to behavioral decision-making. Current Opinion in Behavioral Sciences 5, 91-99.

Lucas J.R. 1961. Minds, machines, and Gödel. Philosophy 36, 112-127.

Marsh L., ed. 2011. Hayek in Mind: Hayek's Philosophical Psychology (Advances in Austrian Economics, Vol. 15). Bingley: Emerald.

Marsh L. 2013. Mindscapes and landscapes: Hayek and Simon on cognitive extension. In Hayek and Behavioral Economics, ed. R. Frantz and R. Leeson, 197-220. Basingstoke: Palgrave Macmillan.

McDowell J.J. 2019. On the current status of the evolutionary theory of behavior dynamics. Journal of the Experimental Analysis of Behavior 111, 130-145.

Mercier H. and D. Sperber 2018. The Enigma of Reason: A New Theory of Human Understanding. London: Penguin Books.

Niedenthal P., L.W. Barsalou, P. Winkielman, S. Krauth-Ruber and F. Ric 2005. Embodiment in attitudes, social perception, and emotion. Personality and Social Psychology Review 9, 184-211.

Northoff G. 2014. Minding the Brain? Introduction to Non-reductive Neurophilosophy. New York, NY: Palgrave Macmillan.

Northoff G. 2016. Cultural neuroscience and neurophilosophy: does the neural code allow for the brain's enculturation? In The Oxford Handbook of Cultural Neuroscience, ed. J.Y. Chiao, S.-C. Li, R. Seligman and R. Turner. Oxford, 21-40. New York, NY: Oxford University Press.

Padoa-Schioppa C. 2011. Neurobiology of economic choice: a good-based model. Annual Review of Neuroscience 34, 333-359.

Padoa-Schioppa C. and K.E. Conen. 2017. Orbitofrontal cortex: a neural circuit for economic decisions. Neuron 968, 736-754.

Papies E.K., L. W. Barsalou and D. Rusz. 2020. Understanding desire for food and drink: a groundedcognition approach. Current Directions in Psychological Science 29, 193-198.

Pezzulo G. and P. Cisek. 2016. Navigating the affordance landscape: feedback control as a process model of behavior and cognition. Trends in Cognitive Sciences 20, 414-424.

Pinker S. 2007. The Stuff of Thought: Language as a Window into Human Nature. New York, NY: Penguin.

Prescott, T.J., J.J Bryson and A.K. Seth 2007. Introduction. Modelling natural action selection. Philosophical Transactions of the Royal Society B: Biological Sciences 362, 1521-1529.

Puglisi G., A. Leonetti, A. Landau, L. Fornia, G. Cerri and P. Borroni 2017. The role of attention in human motor resonance. PLoS ONE 12, e0177457. https://doi.org/10.1371/journal.pone.0177457.

Raichle M.E. 2015. The brain's default mode network. Annual Review of Neuroscience 38, 433-447.

Redcay E. and L. Schilbach 2019. Using second-person neuroscience to elucidate the mechanisms of social interaction. Nature Review Neurosciences 20, 495-505.

Ross D. 2008. Two styles of neuroeconomics. Economics and Philosophy 24, 473-483.

Ross D. 2012. Neuroeconomics and economic methodology. In The Elgar Companion to Recent Economic Methodology, eds. J. B. Davis and D. W. Hands, 61-93, Cheltenham and Northampton: Edward Elgar.

Ross D. 2014. Philosophy of Economics. New York: Palgrave Macmillan.

Rust J. 2011. Hayek, connectionism, and scientific naturalism. In Hayek in Mind: Hayek's Philosophical Psychology (Advances in Austrian Economics, Vol. 15), ed. L. Marsh, 29-50. Bingley: Emerald. 
Rustichini A. and C. Padoa-Schioppa 2015. A neuro-computational model of economic decisions. Journal of Neurophysiology 114, 1382-1398.

Shohamy D. and N.D. Daw 2015. Integrating memories to guide decisions. Current Opinion in Behavioural Sciences 5, 85-90.

Singer T. and C. Lamm 2009. The social neuroscience of empathy. Annals of the New York Academy of Sciences 1156, 81-96.

Smith V. 2004. Constructivist and ecological rationality in economics. American Economic Review 93, 465-508.

Solms M. and K. Friston 2018. How and why consciousness emerges: some considerations from physics and physiology. Journal of Consciousness Studies 25, 202-238.

Spunt R.P. 2015. Dual-process theories in social cognitive neuroscience. In Brain Mapping: An Encyclopedic Reference, Vol. 3, ed. A.W. Toga, 211-215. Amsterdam: Elsevier.

Steele G.R. 2002. Hayek's sensory order. Theory and Psychology 12, 387-409.

Strack F. and R. Deutsch. 2004. Reflective and impulsive determinants of social behaviour. Personality and Social Psychology Review 8, 220-247.

Sugden R. 2018. The Community of Advantage: A Behavioural Economist's Defence of the Market. Oxford: Oxford University Press.

Takahashi T. and S. Egashira 2013. Hayek's Sensory Order, gestalt neuroeconomics, and quantum psychophysics. In Hayek and Behavioral Economics, ed. R. Frantz and R. Leeson, 177-196. Basingstoke: Palgrave Macmillan.

Thaler R.H. 2016. Behavioral economics: past, present, and future. American Economic Review 106, 15771600.

Trepel C., C.R. Fox and P.A. Poldrack 2005. Prospect Theory on the brain? Toward a cognitive neuroscience of decision under risk. Cognitive Brain Research 23, 34-50.

Vanberg V.J., ed. 2018. The 'knowledge problem' as the integrating theme in F.A. Hayek's oeuvre: an introduction to The Sensory Order. In The Collected Works of F. A. Hayek, Vol. XIV. London: Routledge.

Verschure P.F.M.J. 2016. Synthetic consciousness: the distributed adaptive control perspective. Philosophical Transactions of the Royal Society B: Biological Sciences 371, 20150448.

Wiers R.W. and T.W. Gladwin 2017. Reflective and impulsive processes in addiction and the role of motivation. In Reflective and Impulsive Determinants of Human Behaviour, ed. R. Deutsch, B. Gawronski and W. Hofmann, 173-188. New York, NY: Routledge.

Wiers R.W., S. van Gaal and M.E. Le Pelley 2020. Akrasia and addiction: neurophilosophy and psychological mechanisms. In Social Neuroeconomics: Mechanistic Integration of the Neurosciences and the Social Sciences, ed. J. Harbecke and C. Herrmann-Pillath, 121-147. London: Routledge.

Zak P.J., A.A. Stanton and S. Ahmadi 2007. Oxytocin increases generosity in humans. PLoS ONE 2, e0001128. https://doi.org/10.1371/journal.pone.0001128.

Carsten Herrmann-Pillath is Professor and Permanent Fellow at the Max Weber Centre for Advanced Cultural and Social Studies at Erfurt University, Germany. His recent books include: Foundations of Economic Evolution: A Treatise on the Natural Philosophy of Economics (Edward Elgar, 2013), and (with Ivan Boldyrev) Hegel, Institutions and Economics: Performing the Social (Routledge, 2014). His current research focuses on the transdisciplinary integration of economics and the sciences. With Jens Harbecke, he co-edited the volume Social Neuroeconomics: Mechanistic Integration of the Neurosciences and the Social Sciences (Routledge 2020). A current project, with Fréderic Basso, is exploring the idea of an 'embodied economics'. Website: www.cahepil.net

Cite this article: Herrmann-Pillath C (2021). Evolutionary mechanisms of choice: Hayekian perspectives on neurophilosophical foundations of neuroeconomics. Economics and Philosophy 37, 284-303. https:// doi.org/10.1017/S0266267120000371 